\title{
A comparative study on regional cerebral oxygen saturation and central venous oxygen saturation as predictors of outcome in patients on off-pump coronary artery bypass graft surgery
}

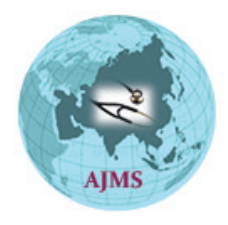

\author{
Shruti Kundu', Sankar Roy ${ }^{2}$, Debajyoti Sur ${ }^{3}$, Arunava Biswas ${ }^{4}$ \\ ${ }^{1}$ Senior Resident, ${ }^{2}$ Associate Professor, ${ }^{3}$ Assistant Professor, Department of Anaesthesiology, R. G. Kar Medical \\ College and Hospital, Kolkata, West Bengal, India, ${ }^{4}$ Associate Professor, Department of Pharmacology, Maharaja \\ Jitendra Narayan Medical College and Hospital, Cooch Behar, West Bengal, India
}

\section{A B S T R A C T}

Background: Off-pump coronary artery bypass grafting (OPCABG) is a common and acceptable surgery. Aims and Objectives: The study was conducted to compare central venous oxygen saturation $\left(\mathrm{ScvO}_{2}\right)$ and regional cerebral oxygen saturation $\left(\mathrm{rSO}_{2}\right)$ to see which of the two is better predictor for the prognosis of patients undergoing OPCABG. Heart rate (HR), invasive blood pressures, and partial pressure of oxygen (pO2) have also been recorded to see if they are independent predictors of prognosis in OPCABG patients. Materials and Methods: A total of 56 patients undergoing OPCABG were included in the study. Baseline values and intraoperative values of ScvO2, rSO2, HR, systolic blood pressure (SBP), diastolic blood pressure (DBP), mean arterial pressure (MAP), pO2 at different time periods were recorded. Post-operatively the patient was shifted to intensive care unit (ICU) in intubated condition, and time to extubation since shifting to ICU was noted. Results: The ScvO2 values after sternal closure (correlation coefficient $r=-0.4821$, $\mathrm{P}=0.0002$ ), and on shifting to ICU (correlation coefficient $\mathrm{r}=-0.4575, \mathrm{P}=0.0004$ ) showed good correlation with time to extubation. Similarly, the rSO2 values after sternal closure (correlation coefficient $\mathrm{r}=-0.5198, \mathrm{P}<0.0001$ ) and on shifting to ICU (correlation coefficient $r=-0.5498, P<0.0001$ ) showed good correlation with time to extubation. HR SBP, DBP, MAP, pO2 individually did not show any correlation with time to extubation ( $P>0.05)$. Conclusion: $\mathrm{ScvO} 2$ and $\mathrm{rSO} 2$ both have strong correlation with time to extubation and are Access this article online

Website:

http://nepjol.info/index.php/AJMS DOI: 10.3126/ajms.v13i2.40906 E-ISSN: 2091-0576

P-ISSN: 2467-9100

Copyright (c) 2022 Asian Journal of Medical Sciences

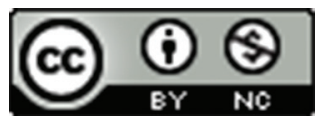

This work is licensed under a Creative Commons Attribution-NonCommercial 4.0 International License.

Key words: Central venous oxygen saturation; Extubation; Off-pump coronary artery bypass grafting; Regional cerebral oxygen saturation

\section{INTRODUCTION}

Coronary artery bypass grafting $(\mathrm{CABG})$ has been shown to be lifesaving in patients unsuitable for coronary angioplasty. Currently, off-pump coronary artery bypass graft surgery $(\mathrm{OPCABG})$ is done for myocardial revascularization in the majority of heart units in the developing countries for economic constraints. The role of cardiac stabilization and positioning of the heart is achieved with stabilization devices, in combination with deep pericardial traction sutures, enabling surgeon to perform multivessel coronary revascularization in beating heart. This strategy obviates the deleterious effects of cardiopulmonary bypass associated with on-pump CABG. ${ }^{1}$ However, even this procedure carries a significant risk of major complications. Associated comorbid conditions of the patient and positioning of the heart during the procedure significantly hampers oxygenation of the vital organs which post-operatively cumulates as increased risk of morbidity and mortality in terms of multiple organ system dysfunction. 
In an attempt to reduce these complications numerous studies and trials have been carried out for the adoption of goal-directed, evidence-based, and hemodynamic treatment strategies. Apart from monitoring of hemodynamic parameters, certain variables of optimal cerebral perfusion have gained impetus.

Central venous oxygen saturation $(\mathrm{ScvO} 2)$ has been suggested as one of the goals to address the issue of adequate cardiovascular circulatory function in the context of cardiac surgeries. ${ }^{2}$ It is an excellent indicator of match/mismatch between cardiac output (CO), arterial oxygen saturation, and hemoglobin $(\mathrm{Hb})$ level as determinants of oxygen delivery and oxygen consumption. ${ }^{2}$

Cerebral oximeters determine regional $\mathrm{Hb}$ oxygen saturation regional cerebral oxygen saturation $\left(\mathrm{rSO}_{2}\right)$ in the frontal lobes by using specially designed probes. These probes comprise adhesive pads containing diodes light-emitting diode or laser light sources that emit photons in the near-infrared (NIR) spectrum capable of tissue penetration of several centimeters through cranial bone to the underlying cerebral tissue. Contact with $\mathrm{Hb}$ molecules results in a change of light spectrum depending on the oxygenation status of $\mathrm{Hb}$. The monitor differentiates the two forms of oxygenated and deoxygenated $\mathrm{Hb}$ using specific computational algorithms in order to determine the $\mathrm{rSO}_{2}$ in the frontal lobes. $\mathrm{rSO} 2$ measured by NIR spectroscopy (NIRS) non-invasively detects brain hypoperfusion. Its primary aim is to detect cerebral oxygen demand and supply. ${ }^{3}$ Fluctuations during intra-operative period can result in temporary brain hypoperfusion. If these periods are sustained, permanent neurological injury may ensue. Neurological injury can therefore be prevented if effective and goal-oriented monitoring detects potentially harmful conditions early enough to allow initiation of effective interventions before irreversible injury has occurred.

\section{Aims and objectives}

The primary aim of this study was to investigate which of the two parameters ScvO2 or rSO2 was a better predictor of prognosis in OPCABG patients considering the prognosis marker as "time taken for extubation of the patient" after shifting to intensive care unit (ICU). The secondary objective was to record heart rate (HR), invasive blood pressure, partial pressure of oxygen (pO2) in arterial blood (po2) and ascertain them as independent predictors for the prognosis of the patients.

\section{MATERIALS AND METHODS}

After obtaining Institutional Ethical Committee clearance (Memo No. IPGMER/IEC/2017/003 Dated 31.01.2017) this prospective observational longitudinal study was carried out in the cardiothoracic and vascular surgery operation theatre (OT) and ICU, at Institute of Post Graduate Medical Education and Research (IPGMER) on 56 patients undergoing elective OPCABG during the period January 2017-August 2018 to explore the impact of various predictors, especially rSO2 and $\mathrm{ScvO} 2$ on outcome in OPCABG patients.

To estimate the sample size "time to extubation" as primary outcome measure was taken into consideration. Assuming a linear relationship between an oxygenation parameter and time to extubation, the sample size was calculated to achieve a sample correlation coefficient of 0.5 . It was estimated that $(n=47)$ patients were required with $80 \%$ power and $5 \%$ probability of type I error, assuming a population correlation coefficient of 0.75 . Sample size calculation was done by nMaster 2.0 software (Department of Biostatics, Christian Medical College, Vellore).

Patients of either sex, aged over 18 years undergoing elective OPCABG were included in the study. Those with a history of cerebrovascular accident with persistent neurological residue, unilateral occlusion of the carotid artery, combined cardiac procedures, left ventricular ejection fraction $<30 \%$, uncontrolled diabetes mellitus, left main coronary artery (LMCA) disease, LMCA equivalent disease, serum creatinine $>2 \mathrm{mg} / \mathrm{dl}$ were excluded from the study. In case of the procedure being converted to on-pump, it was also excluded from the study.

Thorough pre-anesthetic check-up was done and written informed consent was obtained on day before surgery. On day of surgery, patient on being shifted to OT, Spo2, ECG, non-invasive blood pressure, and NIRS monitor were attached to capture various vital parameters. Arterial line was done in the left hand under local anesthesia, and a baseline ABG was recorded.

After pre-oxygenating, the patient, induction was done with Inj. Fentanyl 2-3 $\mu \mathrm{g} / \mathrm{kg}$, Inj Thiopentone 4-5 mg/kg, and Inj. Midazolam 0.1-0.2 mg/kg. Patient was intubated for $90 \mathrm{~s}$ after Inj Rocuronium $1-1.5 \mathrm{mg} / \mathrm{kg}$ administration. Central line and pulmonary artery catheter were inserted. A pre-incision value of all the variables was recorded. Maintenance of anesthesia was done by inhalation Isoflurane, Inj Midazolam, Inj Fentanyl, and Inj Vecuronium. Inj Heparin $1 \mathrm{mg} / \mathrm{kg}$ was administered before grafting and was repeated hourly as $0.5 / \mathrm{kg}$ to maintain activated clotting time (ACT) between 200 and 300s. After completion of grafting heparin activity was reversed by Inj Protamine as $1.3 \mathrm{mg} / \mathrm{kg}$ of the initial heparin dose and ACT were rechecked. After closure of the surgical wound patients were transferred to ICU with endotracheal tube in situ. Patient was monitored and time to extubation since shifting was noted. 
The variables rSO2, ScvO2, invasive blood pressures - systolic blood pressure (SBP), diastolic blood pressure (DBP), and mean arterial pressure (MAP), HR were recorded at the pre-incision, after sternotomy, each grafting, sternal closure and shifting to ICU, respectively.

Data were summarized by routine descriptive statistics, namely mean and standard deviation for normally distributed numerical variable, median and interquartile for skewed numerical variable, and counts and percentages for categorical variables. Association between numerical variables was quantified by calculating Pearson's Rank correlation coefficient " $\mathrm{R}$ " after examination for linear relation through construction of scatter plots. Data were analyzed using Statistica version 6 (Tulsa, Oklahama: statsoft Inc, 2011) and Medcalc version 11.6 (Mariakerke, Belgium: Medcalc software 2011).

All data were found to be normally distributed by Kolmogorov-Smirnov goodness-of-fit test. If good correlations were observed, then an attempt was made to build up regression equation to predict extubation time on the basis of numerical predictors.

\section{RESULTS}

A total of $(n=56)$ patients were assessed during the entire study period as per inclusion/exclusion criteria. The demographic profile of the study participants were presented in Table 1.

The changes observed in $\mathrm{rSO} 2(\mathrm{Mean} \pm \mathrm{SD})$ value from both right and left hemispheres of the brain were recorded at various time intervals and were depicted in Table 2.

There is no statistically significant difference observed between $\mathrm{rSO} 2$ of the left and right hemispheres $(\mathrm{P}>0.05)$. Thus, instead of considering rSO2Lt and rSO2Rt values separately, their mean values ( $\mathrm{rSO} 2$ values) were considered. While comparing the rSO2 value with Pearson's correlation coefficient it was noted that the rSO2 values after graft 3 , sternotomy closure, and on shifting to ICU closely correlate with the time taken for extubation (Table 3).

\begin{tabular}{|c|c|c|c|}
\hline Variables & Minimum & Maximum & $\begin{array}{c}\text { Mean } \pm S D \\
(n=56)\end{array}$ \\
\hline Age (years) & 35 & 68 & $54.64 \pm 8.114$ \\
\hline Height (cms) & 138.00 & 177.0 & $157.67 \pm 6.944$ \\
\hline Weight (kg) & 44.0 & 76.0 & $57.65 \pm 6.461$ \\
\hline BSA & 1.31 & 1.90 & $1.58 \pm 0.014$ \\
\hline CBG & 80 & 130 & $100.32 \pm 1.39$ \\
\hline Hemoglobin (mg \%) & 9.4 & 16.2 & $13.04 \pm 1.568$ \\
\hline
\end{tabular}

The level of significance of $\mathrm{rSO} 2$ with 95\% confidence interval (-0.6886-0.2976) and correlation coefficient $\mathrm{r}$-value of -0.5198 at the time to extubation after sternal closure was found to be statistically highly significant $(\mathrm{p}<0.0001)$ as shown in Figure 1.

The level of significance of $\mathrm{rSO} 2$ with $95 \%$ confidence interval $(-0.7101-0.3354)$ and correlation coefficient r-value of -0.5498 at the time to extubation after shifting to ICU was also found to be statistically highly significant $(\mathrm{p}<0.0001)$ as shown in Figure 2.

When the ScrO2 level was analyzed with Pearson's coefficient at sternotomy closure and on shifting to ICU, they closely correlated with the time taken for extubation with $(\mathrm{P}<0.05)$ (Table 4).

The level of significance of $\mathrm{ScvO} 2$ with 95\% confidence interval (-0.6612-0.2510) and correlation coefficient $\mathrm{r}$-value of -0.4821 at the time to extubation after sternal

\begin{tabular}{|c|c|c|}
\hline rSO2 (\%) & Mean \pm SD & $\begin{array}{l}\text { P-valve } \\
\text { (Paired } \\
\text { t-tests) }\end{array}$ \\
\hline Lt-baseline & $55.79 \pm 7.286$ & 0.788 \\
\hline Rt-baseline & $55.64 \pm 7.873$ & \\
\hline Lt-pre incision & $55.41 \pm 9.862$ & 0.544 \\
\hline Rt-pre incision & $55.77 \pm 9.473$ & \\
\hline Lt-after sternotomy & $55.36 \pm 9.640$ & 0.392 \\
\hline Rt-after sternotomy & $55.91 \pm 8.635$ & \\
\hline Lt-LAD graft & $51.13 \pm 11.132$ & 0.666 \\
\hline Rt-LAD graft & $51.39 \pm 11.685$ & \\
\hline Lt-graft 2 & $48.27 \pm 10.522$ & 0.253 \\
\hline Rt-graft 2 & $48.98 \pm 10.845$ & \\
\hline Lt-graft 3 & $48.73 \pm 10.541$ & 0.253 \\
\hline Rt-graft 3 & $48.73 \pm 9.786$ & \\
\hline Lt-after sternal closure & $50.55 \pm 9.643$ & 0.880 \\
\hline Rt-after sternal closure & $50.64 \pm 9.046$ & \\
\hline Lt-ICU & $51.63 \pm 8.130$ & 0.157 \\
\hline Rt-ICU & $52.23 \pm 8.155$ & \\
\hline
\end{tabular}

Table 3: Pearson's correlation coefficients for rSO2 (coefficient in bold is significant at $\mathrm{P}<0.05$ )

\begin{tabular}{lc} 
rSO2 (\%) & Time to extubation \\
\hline Baseline & -0.29 \\
Pre incision & -0.25 \\
After sternotomy & -0.33 \\
LAD & -0.48 \\
Graft 2 & -0.46 \\
Graft 3 & -0.58 \\
After sternal closure & -0.54 \\
ICU & -0.56 \\
\hline
\end{tabular}

ICU: Intensive care unit, rSO2: Regional cerebral oxygen saturation, LAD: Left anterior descending branch of the coronary arteries 


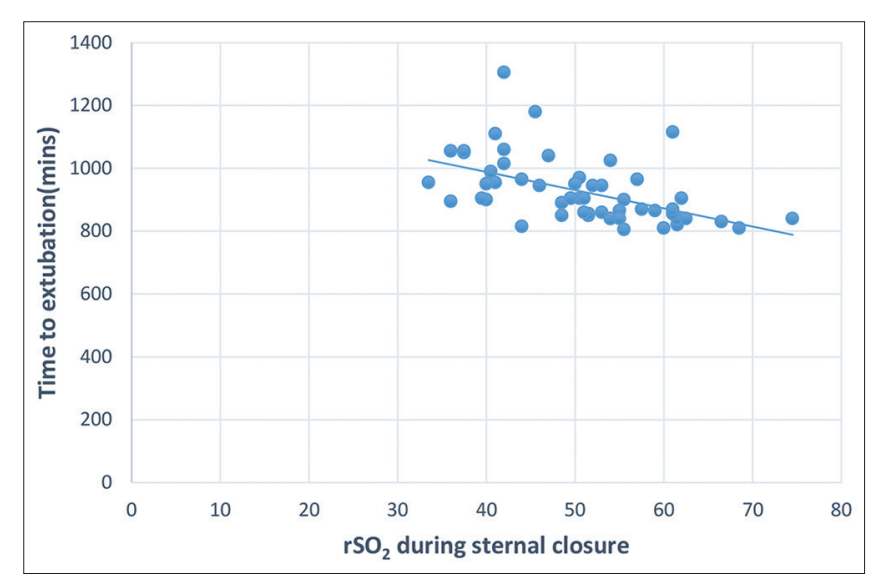

Figure 1: Scatter plot of time to extubation by regional cerebral oxygen saturation after sternal closure

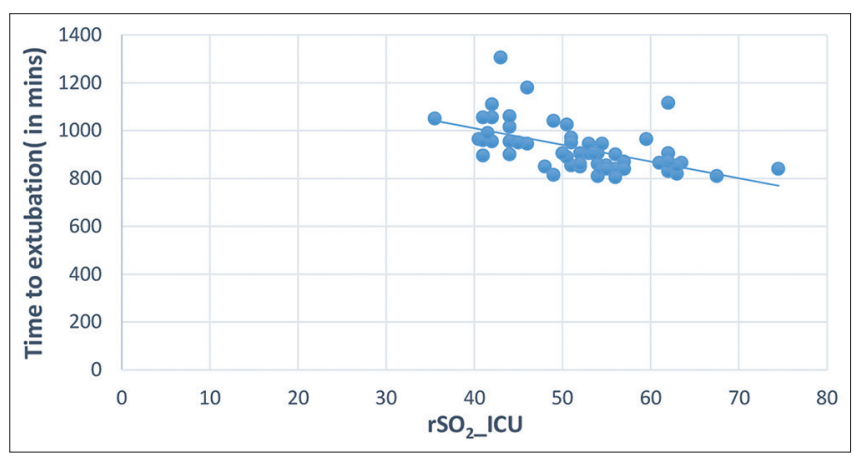

Figure 2: Scatter plot of time to extubation by regional cerebral oxygen saturation on shifting to intensive care unit

\begin{tabular}{lc}
$\begin{array}{l}\text { Table 4: Pearson's correlation coefficients } \\
\text { for ScvO2 (coefficient in bold is significant at } \\
\text { P<0.05) }\end{array}$ \\
\hline ScvO2 (\%) & $\begin{array}{c}\text { Time to } \\
\text { extubation }\end{array}$ \\
\hline Baseline & -0.47 \\
After sternotomy & -0.47 \\
ScvO2_LAD & -0.35 \\
ScvO2_graft 2 & -0.47 \\
ScVO2_graft 3 & -0.45 \\
ScrO2_after sternal closure & -0.56 \\
ScvO2_ICU & -0.54 \\
\hline ICU: Intensive care unit, ScvO2: Central venous oxygen saturation, LAD: Left \\
anterior descending branch of the coronary arteries
\end{tabular}

closure was found to be statistically highly significant $(\mathrm{P}=0.00) 02)$ as shown in Figure 3.

The level of significance of $\mathrm{ScvO} 2$ with $95 \%$ confidence interval (-0.6431-0.2212) and correlation coefficient r-value of -0.4575 at the time to extubation after shifting to ICU was also found to be statistically highly significant $(p=0.0004)$ as shown in Figure 4.

The rSO2 values and the $\mathrm{ScvO} 2$ values after sternal closure and on shifting to ICU showed the strong correlation with

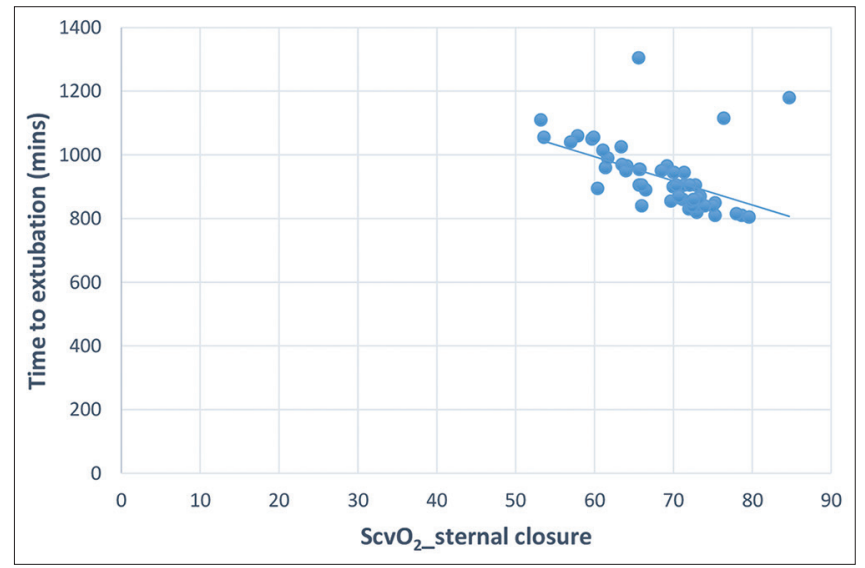

Figure 3: Scatter plot of time to extubation by central venous oxygen saturation after sternal closure

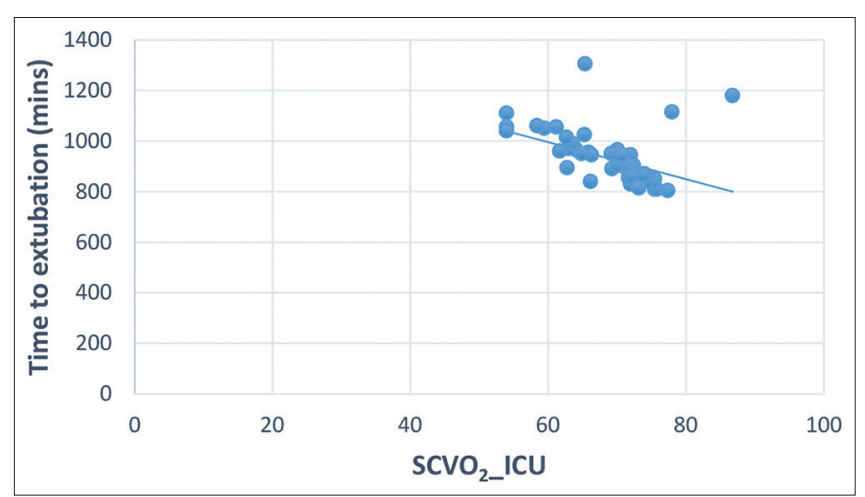

Figure 4: Scatter plot of time to extubation by central venous oxygen saturation on shifting to intensive care unit

time to extubation of the patient. The other parameters HR, SBP, DBP, MAP, and pO2 individually did not show any correlation with time to extubation and were found to be statistically insignificant.

\section{DISCUSSION}

Hemodynamic instability throughout the positioning, stabilization and interruption of coronary blood flow are important factors that affect the performance of off-pump surgery. ${ }^{4}$ Scientific literature demonstrates that the application of specific monitoring may be able to enhance the detection of hypoxic conditions associated with neurological sequelae and would allow intervention on individual patients and drive refinements in strategies to reduce patients at risk. ${ }^{5}$

ScvO2 measures oxygen saturation of blood returning from the upper body. Its normal value ranges from $70 \%$ to $80 \%$. Values $<50 \%$ denote exhaustion of resources and beginning of lactic acidosis. ${ }^{6}$

Normal $\mathrm{rSO}_{2}$ values, prior to the induction of general anesthesia, range from $60 \%$ to $80 \%$. Although lower values 
(55-60\%) for cardiac surgery patients breathing room air are not considered atypical. ${ }^{7}$ Besides cerebral oxygenation, baseline cerebral oximetry values reflect a patient's overall cardiopulmonary function and systemic oxygen needs. Successful treatment increased $\mathrm{rSO}_{2}$ values.

Shepherd and Pearse states that decrease in $\mathrm{ScvO} 2$ is seen in conditions of alveolar hypoventilation, anemia, heart failure, hypovolemia, pain, agitation, pyrexia, shivering, and respiratory failure. Whereas oxygen therapy, blood transfusion, intravenous fluids, inotropes, sedation, anesthesia, analgesia, warming, respiratory support brings about an improvement in $\mathrm{ScvO}$ 2. It concludes that the use of venous oxygen saturation as a therapeutic goal for hemodynamic therapy may reduce postoperative complication rates. ${ }^{8}$

Predictors of cerebral oxygen saturation included partial pressure of carbon dioxide, pump flow rate (LMP), temperature, MAP, hematocrit, $\mathrm{HR}$, and oxygen saturation (SpO2). ${ }^{9}$

The current study showed that both these oxygenation parameters have a good correlation with the time to extubation of the patient, especially after sternal closure and on shifting to ICU. The values of the variables at these time periods have a better correlation with the prognosis of patient. Suggesting they can be used as surrogate measures of each other, and a correlation may exist between them. Factors influencing the cerebral physiology and these two oxygenation parameters are varied. Hence, interventions to keep it within physiological limit has to be individualized. van Beest et al., concluded that low venous oxygen saturation are important signs for inadequacy to meet oxygen demands. Low values may warn the clinician about cardiocirculatory or metabolic impairment and should urge for further diagnostics and appropriate action, whereas normal or high valve do not rule out persistent tissue hypoxia. ${ }^{10}$

Nebout and Pirrachio concluded ScrO2 measurement is an interesting tool, especially in the early stages of shock to guide fluid management and blood transfusion and inotropic support. ${ }^{11}$ Paarmann et al., concluded that $\mathrm{rSO} 2$ assessment prior to cardiac surgeries is significantly related to time to extubation, and may thus be used to stratify candidates in fast track programs. ${ }^{3}$ In the current study, the rSO2 values towards the end of surgery showed greater significance in terms of extubation of patient. In this study, fast track cardiac anesthesia was not practised.

Schreen et al., states that NIRS offers noninvasive online monitoring of tissue oxygenation in a wide range of clinical scenarios. A common application is to measure $\mathrm{rSO} 2$ during cardiac surgeries. ${ }^{12}$
Moritz et al., concluded positioning of the heart during off-pump CABG (OPCABG) leads to a decrease in $\mathrm{rSO}_{2}$. This decrease is associated with changes in CO, $\mathrm{Hb}$ concentration, arterial $\mathrm{CO} 2$ partial pressure, and central venous pressure. ${ }^{13}$ de Tournay-Jetté et al., showed intraoperative cerebral oxygen desaturation is associated with early and late post-operative cognitive dysfunction in elderly patients. Cerebral oximetry is a promising tool in the prediction of subtle neuropsychiatric deficits and further studies are needed. ${ }^{14}$ Harilall et al., showed the correlation between central venous saturation and cerebral saturation in the study and indicated that central venous saturation can be used as a surrogate measure of cerebral oxygen saturation, for neurologically asymptomatic patients undergoing OPCAB. The study further stated that with every one unit increase in left cerebral oxygen saturation, there was a corresponding 0.760 unit increase in $\mathrm{ScvO}_{2}$ And with every one unit increase in right cerebral oxygen saturation, there was a corresponding 0.879 unit increase in $\mathrm{ScvO}_{2}{ }^{15}$

McQuillen et al., study on the association between regional and $\mathrm{ScvO}_{2}$ in pediatric cardiac surgery concluded that neither individual values, nor changes in $\mathrm{rSO} 2$ are interchangeable measures of $\mathrm{ScvO} 2$ in postoperative pediatric cardiac patients. ${ }^{16}$

Coronary artery disease is a disease of the adult population, and cardiac surgery in pediatric population was not considered in the current study. The mean age in the current study was $54.64 \pm 8.114$. Kakuta et al., in a case report noted that $\mathrm{ScvO} 2$ shows more marked changes than $\mathrm{rSO} 2$, a combination of these two parameters for monitoring during Glenn shunt may be safer. ${ }^{17}$

$\mathrm{ScvO} 2$ and $\mathrm{rSO} 2$ can both or either be used depending on the economic constraints, and OT set up to guide therapy during OPCABG. ScvO2 is attractive as is readily measurable without any additional monitoring technology. Central venous line is routinely placed in every patient undergoing OPCABG. Even if continuous $\mathrm{ScvO} 2$ monitoring by a spectrophotometer is not done, intermittent evaluation after significant events can be equally useful. $\mathrm{rSO} 2$ by NIRS is a noninvasive method, but it requires new equipments and disposable sensors which may not be economical. Further, it has the risk of interference from dirt, skin pigmentation, disconnection leading to false readings. The limitations of the study were small sample size, events in the ICU were not documented which may have influenced the extubation time, continuous monitoring of $\mathrm{ScvO} 2$ with spectrophotometer was not done and whole rSO2 was continuously monitored by NIRS.

\section{Limitations of the study}

The limitations of the study were small sample size, events in the ICU were not documented which may have 
influenced the extubation time, continuous monitoring of $\mathrm{ScvO} 2$ with spectrophotometer was not done and whole rSO2 was continuously monitored by NIRS.

\section{CONCLUSION}

ScvO2 and rSO2 can be important and reliable parameters used in guiding and predicting the prognosis of patients undergoing OPCABG. As they are the cumulative effects of many interplaying factors, hence are better predictors than other individual hemodynamic factors. Choosing between the two modalities will depend on individualization for the undergoing procedure, patient and institutional infrastructure.

\section{REFERENCES}

1. Bowles BJ, Lee JD, Dang CR, Toaka SN, Johnson EW, Lau EM, et al. Coronary artery bypass performed without the use of cardiopulmonary bypass is associated with reduced cerebral microemboli and improved clinical result. Chest. 2001;119(1):25-30.

https://doi.org/10.1378/chest.119.1.25

2. Balzer $F$, Sander $M$, Simon $M$, Spies $C$, Habicher $M$, Treskatsch S, et al. High central venous saturation after cardiac surgery is associated with increased organ failure and long term mortality: An observational study. Crit Care. 2015;19(1):168.

https://doi.org/10.1186/s13054-015-0889-6

3. Paarmann $H$, Hanke $T$, Heringlake $M$, Heinze $H$, Brandt $S$ and Brauer K. Low preoperative cerebral oxygen saturation is associated with longer time to extubation during fasttrack cardiac anaesthesia. Interact Cardiovasc Thorac Surg. 2012;15(3):400-405.

https://doi.org/10.1093/icvts/ivs228

4. Mishra M, Shrivaztava S, Dhara A, Bapna R, Mishra A, Meharwal ZS, et al. A prospective evaluation of hemodynamic instability during off-pump coronary artery bypass surgery. J Cardiothorac Vasc Anesth. 2003;17(4):452-458.

https://doi.org/10.1016/S1053-0770(03)00149-6

5. Hoffman GM. Neurologic monitoring on cardiopulmonary bypass: What are we obligated to do? Ann Thorac Surg. 2006;81(6):S2373-S2380.

https://doi.org/10.1016/j.athoracsur.2006.02.076

6. Reyer E. DNP, ACNP, CCNS: The Hemodynamic and Physiological Relevance of Continuous Central Venous Oxygenation Monitoring: It's Not Just for Sepsis; 2013. Available from: https://smj.journals.ekb.eg/article_46216.html [Last accessed on 2021 Aug 12].

7. Vretzakis G, Georgopoulou S, Stamoulis K, Stamatiou G,
Tsakirisis K, Zarogoulidis P, et al. Cerebral oximetry in cardiac anaesthesia. J Thorac Dis. 2014;6 Suppl 1:60-69.

https://doi.org/10.3978/j.issn.2072-1439.2013.10.22

8. Shepherd SJ and Pearse RM. Role of central and mixed venous oxygen saturation measurement in perioperative care. Anaesthesiology. 2009;111(3):648-656. https://doi.org/10.1097/ALN.0b013e3181af59aa

9. Harilall $\mathrm{Y}$, Adam JK, Biccard BM and Reddi A. The effect of optimising cerebral tissue oxygen saturation on markers of neurological injury during coronary artery bypass graft surgery. Heart Lung Circ. 2014;23(1):68-74. https://doi.org/10.1016/j.hlc.2013.07.002

10. Beest PV, Wietasch G, Scheeren T, Spronk P and Kulper M. Clinical review: Use of venous oxygen saturations as a goal-a yet unfinished puzzle. Crit Care. 2011;15(2):232. https://doi.org/10.1186/cc10351

11. Nebout $S$ and Pirrachio R. Review article: Should we monitor ScvO2 in critically ill patients? Cardiol Res Pract. 2012;2012:370697.

https://doi.org/10.1155/2012/370697

12. Schreen TW, Schober $R$ and Schwarte LA. Monitoring tissue oxygenation by near infrared spectroscopy (NIRS): Background and current applications. J Clin Monit Comput. 2012;26(4):279-287. https://doi.org/10.1007/s10877-012-9348-y

13. Moritz S, Rochon J, Volkel S, Hilker M, Hobbhahn J, Graf BM, et al. Determinants of cerebral oximetry in patients undergoing off-pump coronary artery bypass grafting: An observational study. Eur J Anaesthesiol. 2010;27(6):542-549. https://doi.org/10.1097/eja.0b013e3283343ef8

14. Tournay-Jette E, Dupuis G, Bherer L and Deschamps A. The relationship between cerebral oxygen saturation changes and postoperative cognitive dysfunction in elderly patients after coronary artery bypass graft surgery. J Cardiothorac Vasc Anesth. 2011;25(1):95-104. https://doi.org/10.1053/j.jvca.2010.03.019

15. Harilall Y, Adam JK, Biccard BM and Reddi A. Correlation between cerebral tissue and central venous oxygen during off-pump coronary bypass graft surgery. Perfusion. 2011;26(2):83-90. https://doi.org/10.1177/0267659110387846

16. Mcquillen PS, Nishimoto MS, Bottrell CL, Lori D, Fineman MA, Hamrick SE, et al. Regional and central venous oxygen saturation monitoring following pediatric cardiac surgery: Concordance and association with clinical variables. Pediatr Crit Care Med. 2007;8(2):154-160. https://doi.org/10.1097/01.pcc.0000257101.37171.be

17. Kakuta N, Kawahito S, Mita N, Kambi N, Kasai A, Wakamatsu N, et al. Usefulness of central venous oxygen saturation monitoring during bidirectional Glenn shunt. J Med Invest. 2013;60(3-4):272-275.

https://doi.org/10.2152/jmi.60.272

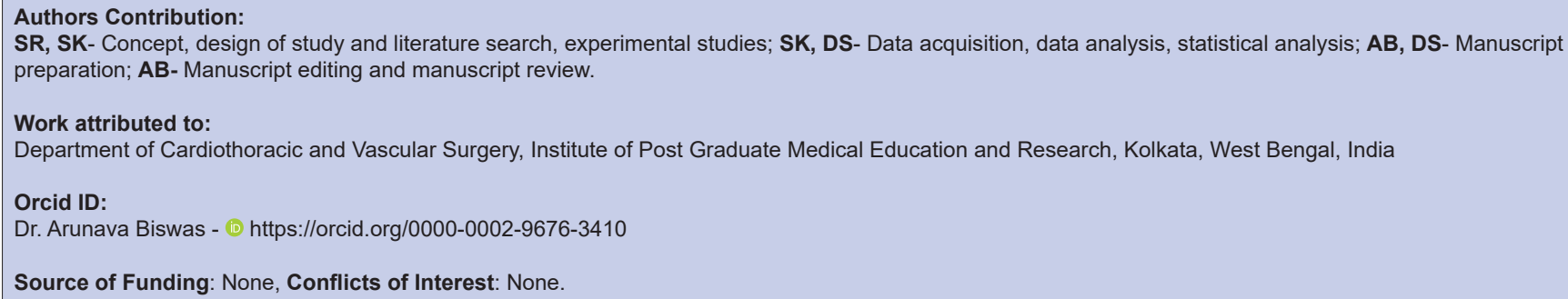

